\title{
Neonatal resuscitation assessment: documentation and early paging must be improved!
}

\author{
Sophie Berglund, ${ }^{1}$ Mikael Norman²
}

'Department of Clinical Sciences, Karolinska Institutet, Danderyd Hospital, Stockholm, Sweden

${ }^{2}$ Department for Clinical Science, Intervention and Technology, Karolinska Institutet, Stockholm, Sweden

\section{Correspondence to} Dr Sophie Berglund, Department of Obstetrics and Gynecology, Danderyds Sjukhus AB, S-182 88 Stockholm, Sweden; sophie.berglund@ds.se

Accepted 28 August 2011 Published Online First 27 October 2011
This paper is freely available online under the BMJ Journals unlocked scheme, see http:// adc.bmj.com/info/unlocked.dtl

\begin{abstract}
Objective The authors had previously found flaws in resuscitation after severe neonatal asphyxia in cases selected on the grounds of suspected malpractice and financial compensation claims. The aim of the present study was to evaluate neonatal resuscitation in the general obstetric population in a setting with skilled attendance at birth.
\end{abstract}

Design Observational study.

Setting and patients All infants born in the Stockholm County during 2004-2006 with a gestational age of $\geq 33$ weeks, planned as vaginal delivery, with a normal cardiotocographic recording on admission to hospital and with an Apgar score of $<7$ at 5 min were included.

Main outcome measures Adherence to guidelines for neonatal resuscitation.

Results Documentation was unsatisfactory in 142 $(45 \%)$ infants. Other important shortcomings identified were delayed initiation of extensive resuscitation due to late paging or late arrival of attending paediatrician/ neonatologist $(n=48)$, and unsatisfactory ventilation related to late intubation and late securing of free airway $(n=15)$.

Conclusions Substandard care in neonatal resuscitation is not limited to cases of severe asphyxia related to claims for medical malpractice. The overall documentation of neonatal resuscitation needs to be much better to enable accurate and reliable evaluation. Obvious actions to improve standards of care include the paging of skilled personnel at an earlier stage in cases of complicated deliveries and team and skills training in neonatal ventilation.

\section{INTRODUCTION}

To improve public health and minimise individual suffering, global efforts are in place to improve mother and infant safety in conjunction with childbirth. ${ }^{12}$ However, there are still many cases in which severe neonatal asphyxia could have been avoided. ${ }^{34}$ In developed countries, the insurance costs due to malpractice claims in conjunction with childbirth are steadily increasing and today, they amount to $25 \%$ of all health insurance costs, primarily due to lifelong compensation for severe disabilities caused by asphyxia. ${ }^{1}$

In a previous study of in-hospital childbirth with skilled attendance, we found that as many as two thirds of the infants with low Apgar scores at a postnatal age of $5 \mathrm{~min}$ had been subjected to some kind of substandard obstetric care during labour. ${ }^{5}$ The main pitfalls were misinterpretation of cardiotocography (CTG), not acting timely on abnormal CTG and misuse of oxytocin. We also studied neonatal resuscitation in the most severely

\section{What is already known on this topic}

- Insurance costs due to claims in conjunction with childbirth amount to $25 \%$ of all health insurance costs related to medical malpractice.

- Insufficient adherence to guidelines for neonatal resuscitation is common in such cases.

- It is poorly known if substandard neonatal care is limited to the most severe cases of asphyxia orifitrepresents amorewidespread phenomenon.

\section{What this study adds}

- Substandard care in neonatal resuscitation is not limited to severe cases of asphyxia related to medical malpractice.

- Documentation of neonatal resuscitation needs to be much better to enable accurate and reliable evaluation.

- Standards of care could be improved by earlier paging of skilled personnel in cases of complicated deliveries and by team training and skills training in ventilation.

affected infants with a filed claim for financial compensation due to substandard care. ${ }^{3}$ The most important findings were related with the insufficient adherence to guidelines concerning neonatal resuscitation, and this included delayed initiation of extensive resuscitation, lack of satisfactory ventilation and untimely interruption of resuscitation.

Whether or not the substandard care, previously stated, is limited to the most severe cases or represents a more widespread phenomenon is poorly substantiated. The aim of the present study was therefore to evaluate the adherence to the guidelines for neonatal resuscitation in the general obstetric population.

\section{METHODS}

We studied a population-based cohort recruited at all seven delivery units in the Stockholm County and together it encompassed $24 \%(n=74539)$ of all births in Sweden $(n=309140)$ during years 2004-2006. Infants with an Apgar score of $<7$ at 5 min of age and a gestational age of $\geq 33$ weeks were included. The gestational age was determined by a second trimester ultrasound and the 
infants were identified by the Swedish Medical Birth Register. Four hundred and fifteen infants fulfilled the inclusion criteria. We excluded 102 infants due to a non-reactive CTG at admission $(n=60)$, missing case records or CTG tracings $(n=31)$, precipitate deliveries $(n=7)$ or lethal malformations $(n=4)$. All 313 cases were planned as vaginal deliveries and had normal CTG on admission to the delivery unit, indicating a well-oxygenated fetus at that time.

\section{Data collection}

All case records were similarly scrutinised and computerised by one of the authors (SB), who is a senior consultant in obstetrics, a graduate of the American Neonatal Resuscitation Provider Program and also an instructor of team training in neonatal resuscitation at the Centre for Education in Paediatric Simulator at Södersjukhuset in Stockholm. ${ }^{6}$ The reviewer (SB) had access to all information from each case record and was therefore not blinded to the final outcome.

Data were collected from the standardised obstetric records used throughout Sweden, including CTG recordings, details and complications around labour including the time of paging of a physician, the date and time of birth, gestational age, gender, birth weight, Apgar scores at 1,5 and $10 \mathrm{~min}$, umbilical cord acid-base status, acts of neonatal resuscitation, admission to and length of stay (LOS) in the neonatal intensive care unit (NICU), degree of hypoxic ischaemic encephalopathy (HIE) and investigations during the first weeks of age. Diagnoses during pregnancy and delivery were registered at discharge from hospital. The information on the degree of HIE was retrieved from the neonatal case records (ICD10-codes P91.0, P91.6, P91.6X, P91.6A, P91.6B and P91.6C).

According to national clinical guidelines in obstetrics, the paediatrician should be paged before a birth in cases of imminent asphyxia, in breech and instrumental deliveries, and immediately when deliveries are complicated by shoulder dystocia. In cases of unexpected asphyxia, the target time for the arrival of skilled assistance was set at being within 4 min after birth for a paediatrician and $15 \mathrm{~min}$ for a neonatologist.

According to guidelines used during in the study period (revised late in 2006 and again in 2009), clearing the airways from meconium and initiating bag and mask ventilation with initially $40 \%$ oxygen should be performed immediately on all newborns with a heart rate below 100 beats/min (bpm). In cases of asystolia, endotracheal intubation and the administration of thoracic compressions should be performed immediately. Early intubation (within 2-3 min after birth) was recommended in cases with persistent bradycardia to ensure free airways and satisfactory ventilation. Administration of adrenalin was recommended if the heart rate did not rise despite satisfactory ventilation. Correction of metabolic acidosis should be performed in cases of refractory bradycardia and terminal apnoea. Interruption of resuscitation was to be considered, if there was no evidence of heart activity after 15 min or if no spontaneous breathing or body movements had occurred during the first $30 \mathrm{~min}$ after birth.

Based on these guidelines, we established failure events in conjunction with neonatal resuscitation, summarised in figure 1.

Statistical analyses were done in SPSS 17.0 (SPSS, Chicago, Illinois, USA). Data are presented as median (range) values or as numbers and proportions (\%). The study was approved by the Research Ethics Committee, Karolinska Institutet, Stockholm (no. 2008/1375).

\section{RESULTS}

Forty per cent $(n=124)$ of the 313 infants with Apgar scores of $<7$ at 5 min of age were born by a spontaneous vaginal delivery, $34 \%(n=108)$ by vacuum extraction, $1.6 \%(n=5)$ by forceps and $24 \%(n=76)$ by Caesarean section (CS), 41 of whom were delivered by emergency CS. In one spontaneously delivered infant, labour was complicated by shoulder dystocia and seven infants were vaginally born in breech presentation.

All 313 study infants were subjected to various actions for resuscitation after birth. The median Apgar score at 5 min of age was 5 (range $0-6$ ) (figure 2). At $10 \mathrm{~min}$ of age, 90 infants still had an Apgar score of $<7,21$ of whom had an Apgar score of $\leq 3$ and eight of these infants died later in the neonatal period.

Documentation was defective in many cases. In 16 infants $(5.1 \%)$, there was no documentation on resuscitation and in 126 infants (40\%), documentation was incomplete (table 1).

Three hundred and ten infants (99\%) were subjected to artificial ventilation for a median of $7 \mathrm{~min}$ (range 1-50 $\mathrm{min}$, information on duration missing in 72 infants $(23 \%)$ ). The median time of onset of spontaneous breathing was $10 \mathrm{~min}$, but notation of this constituent part was missing in $43 \% \quad(n=136)$. Ventilation was unsatisfactory in 15 infants and in five of these infants, artificial ventilation was not initiated within 1 min after birth despite apnoea and bradycardia ( $<100$ bpm),

a) Artificial ventilation not started within 1 minute after birth in cases of apnoea and fetal heart rate $<100 \mathrm{bpm}$.

b) Endotracheal intubation not performed within 3 minutes after birth in cases of asystolia or in cases of persistent apnoea and bradycardia.

c) Thoracic compressions not performed despite asystolia.

d) Adrenaline not provided despite asystole or persistent bradycardia.

e) Correction of metabolic acidosis not performed in cases of asystole or persistent bradycardia.

f) Paediatrician or neonatologist not present before birth despite knowledge of delivery complication.

Figure 1 Failure events in conjunction with neonatal resuscitation. 


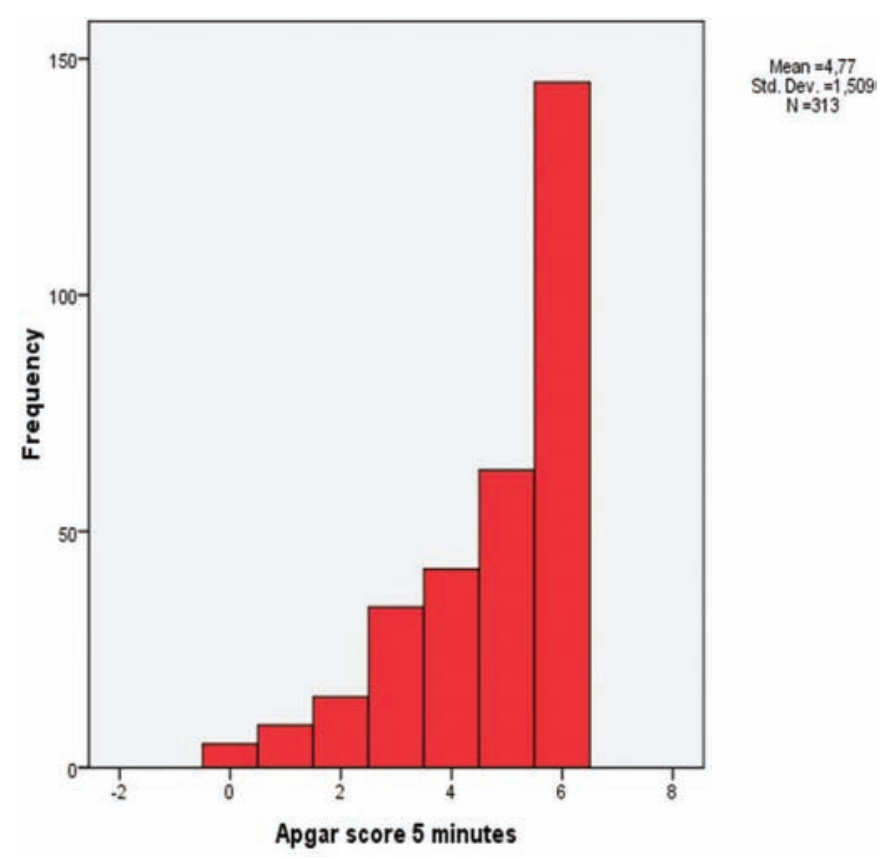

Figure 2 Distribution of Apgar scores at $5 \mathrm{~min}$ in a population-based cohort of 313 moderately preterm and term infants resuscitated at birth.

Table 1 Documentation of neonatal resuscitation in 313 newborn infants with Apgar scores of $<7$ at 5 min of age

\begin{tabular}{lcll}
\hline & $\mathbf{n}(\%)$ & $\begin{array}{l}\text { Apgar score } \\
\leq \mathbf{3} \text { at 10 } \\
\mathbf{m i n}^{*} \text { (n) }\end{array}$ & $\begin{array}{l}\text { Death }^{\dagger} \\
\text { (n) }\end{array}$ \\
\hline $\begin{array}{l}\text { All resuscitation documentation } \\
\text { missing in case record }\end{array}$ & $16(5.1)$ & 0 & 2 \\
$\begin{array}{l}\text { Unsatisfactory documentation, any }{ }^{\ddagger} \\
\text { Acid-base status not documented }\end{array}$ & $126(40)$ & 3 & 3 \\
$\begin{array}{l}\text { Duration of artificial ventilation } \\
\text { lacking }\end{array}$ & $58(19)$ & 5 & 2 \\
$\begin{array}{l}\text { Duration of heart compressions } \\
\text { lacking }\end{array}$ & $72(24)$ & 2 & 2 \\
$\begin{array}{l}\text { Time for spontaneous breathing not } \\
\text { noted }\end{array}$ & $136(46)$ & 1 & 2 \\
$\begin{array}{l}\text { Time for endotracheal intubation not } \\
\text { documented }\end{array}$ & $18(25)$ & 2 & 3 \\
$\begin{array}{l}\text { No arrival time for skilled assistance } \\
\text { in cases of unexpected asphyxia }\end{array}$ & $37(30)$ & 0 & 0 \\
$\begin{array}{l}\text { No arrival time for skilled assistance } \\
\text { in cases of known complicated }\end{array}$ & $27(22)$ & 0 & 0 \\
$\begin{array}{l}\text { vaginal deliveries } \\
\text { Time for correction of acidosis not } \\
\text { documented }\end{array}$ & $110(62)$ & 5 & 3 \\
\hline
\end{tabular}

Flaws in documentation categorised and related to severe asphyxia and/or death. *21 infants had Apgar scores of $\leq 3$ at 10 min of age.

${ }^{\dagger}$ Eight infants died during the neonatal period.

${ }^{\ddagger}$ Available documentation for 297 infants.

§Study group, $\mathrm{n}=313$.

"Heart compressions, $\mathrm{n}=36$.

**Endotracheal intubation, $\mathrm{n}=72$ infants.

${ }^{\dagger \dagger} \mathrm{n}=124$.

${ }^{\ddagger \pm} \mathrm{n}=121 ; 113$ instrumental, 1 with shoulder dystocia and 7 breech deliveries.

and in 10 infants, despite clear indications, intubation was not performed within 3 min after birth. Seven of these infants had an Apgar score of $\leq 3$ at $10 \mathrm{~min}$ of age and three of these infants eventually died (table 2). Endotracheal intubation was performed in 72 infants at a median age of 3 min (range $0-184$ min), but there was no record in the notes of when it actually
Table 2 Deviations from Swedish guidelines for neonatal resuscitation in 2004-2006

\begin{tabular}{|c|c|c|c|c|}
\hline & $n / N$ & $\%$ & $\begin{array}{l}\text { Apgar score } \\
\leq 3 \text { at } 10 \\
\min ^{*}(n)\end{array}$ & $\begin{array}{l}\text { Death } \\
\text { (n) }\end{array}$ \\
\hline Unsatisfactory resuscitation & $17 / 313$ & 5.4 & & \\
\hline $\begin{array}{l}\text { Artificial ventilation not started within } \\
1 \text { min after birth in cases of apnoea and } \\
\text { fetal heart rate }<100 \text { beats/min }\end{array}$ & 5 & 1.6 & 0 & 0 \\
\hline $\begin{array}{l}\text { Endotracheal intubation not performed } \\
\text { within } 3 \text { min after birth }\end{array}$ & 10 & 71 & 7 & 3 \\
\hline $\begin{array}{l}\text { Thoracic compressions not performed } \\
\text { despite asystole }{ }^{\ddagger}\end{array}$ & 2 & 15 & 2 & 1 \\
\hline Unsatisfactory drug administration & 8 & 43 & & \\
\hline $\begin{array}{l}\text { Epinephrine not provided despite } \\
\text { asystole }^{\ddagger} \text { or persistent bradycardia }\end{array}$ & 5 & 36 & 2 & 1 \\
\hline $\begin{array}{l}\text { No correction of metabolic acidosis } \\
\text { despite asystole or persistent } \\
\text { bradycardia }^{\S}\end{array}$ & 1 & 7 & 0 & 0 \\
\hline Buffer despite normal acid-base status & 2 & & 0 & 0 \\
\hline Late arrival & 48 & 15 & & \\
\hline $\begin{array}{l}\text { Paediatrician, neonatologist or } \\
\text { anaesthesiologist not present } \\
\text { before birth" }\end{array}$ & 21 & 17 & 2 & 2 \\
\hline $\begin{array}{l}\text { Paediatrician, neonatologist or } \\
\text { anaesthesiologist not arrived within } \\
4 \text { min after birth** }\end{array}$ & 27 & 22 & 2 & 2 \\
\hline \multicolumn{5}{|l|}{ Untimely interruption of resuscitation } \\
\hline $\begin{array}{l}\text { Resuscitation not interrupted despite } \\
\text { asystole for }>15 \mathrm{~min}\end{array}$ & 3 & 0.96 & 3 & 3 \\
\hline
\end{tabular}

Study group: 313 infants with Apgar scores of $<7$ at $5 \mathrm{~min}$.

*21 infants had Apgar scores of $\leq 3$ at 10 min of age.

${ }^{\dagger}$ Eight infants died during the neonatal period.

$\ddagger_{13}$ infants had asystole at 1 min of age (Apgar score 0 ).

$\S 14$ infants had asystole or persistent bradycardia at 5 min of age (Apgar score $\leq 1$ ).

"Complicated vaginal deliveries ( $\mathrm{n}=121)$.

**In cases of unexpected asphyxia $(n=124)$.

took place in $25 \%(\mathrm{n}=18)$. Twelve infants were intubated at an age of $>10 \mathrm{~min}$ (range $11-40 \mathrm{~min}$ ).

Thirty-six infants were subjected to heart compressions for a median of $3 \mathrm{~min}$ (range 1-22 min; information on duration was missing in eight infants $(22 \%)$ ). Three of the infants for whom resuscitation was not discontinued in accordance with prescribed guidelines (asystole for $>15 \mathrm{~min}$ ) died shortly after birth. Heart compressions were not performed in two infants with asystole at 1 min of age. Both these infants, still had an Apgar score of $\leq 3$ at 10 min of age (table 2).

In 5 of 14 infants with an Apgar score of $\leq 1$ at 5 min of age, two of whom had an Apgar score of $\leq 3$ at $10 \mathrm{~min}$, epinephrine was not administered, and one infant died (table 2).

The $\mathrm{pH}$ and base deficit of blood from a cord artery sample taken immediately after birth were available in $81 \%(\mathrm{n}=255)$. The median $\mathrm{pH}$ was 7.14 (range 6.63-7.44) and the median base deficit was 10 (range 1-28.7). One hundred and seventysix infants were treated with buffer, however, the time point for correction of acidosis was noted in only $38 \%(n=66)$. The median time point for acidosis correction was $15 \mathrm{~min}$ (range 1-150 min). Two infants with a normal acid-base status were also treated with buffer while one infant with asystolia was not treated with buffer (table 2).

Information relating to the attending physician and his/her time of arrival was not routinely noted nor was the level of expertise. The only regular notation was whether a physician at any level of education was present and if a neonatologist had been paged. 
In $27(22 \%)$ of the 121 vaginal deliveries in which abnormalities were noted before delivery and which would normally mandate the presence of a physician (eg, instrumental deliveries, shoulder dystocia or breech deliveries), no such presence (paediatrician, neonatologist or anaesthesiologist) before birth was noted. In cases of unexpected asphyxia $(n=124)$, the time of arrival of the physician was not noted in 37 infants $(30 \%)$ (table 1). The time of arrival exceeded $4 \mathrm{~min}$ in 27 infants, two of whom had an Apgar score of $\leq 3$ at $10 \mathrm{~min}$ and they both died later (table 2).

Two hundred and thirty-one infants (74\%) were admitted to the NICU. The median LOS in the NICU was 4 days (range 1-240), but for the 21 infants being ventilated for more than $24 \mathrm{~h}$ (range 1-10 days) the median LOS was 15 days. Thirtyfive infants were transferred to another hospital shortly after birth, four of whom were treated with hypothermia. Fifty-six $(18 \%)$ infants suffered from convulsions during the neonatal period. The number of infants upon whom EEG was performed could not be retrieved, but notations of abnormal EEG were found in 41 infants.

The degree of HIE was determined in 62 infants. Among those, HIE I was diagnosed in 25, HIE II in 29 and HIE III in 8 infants.

\section{DISCUSSION}

Immediate resuscitation is of crucial importance when a newborn infant is depressed around birth. In our cohort, 5.6 per 1000 moderately preterm or term infants had an Apgar score of $<7$ at 5 min of age, which is in line with previously published national data. ${ }^{7}$ Even if the proportion of newborn infants requiring skilled assistance at birth may be considered to be small, the consequences of not receiving timely and correctly performed resuscitation may be lifelong impairment or even death.

In this population-based study, we found several indicators of substandard care in the neonatal resuscitation of 313 infants with Apgar scores of $<7$ at 5 min of age. The most common flaw was unsatisfactory or lack of documentation of resuscitation, which was observed in almost half of the cases. This does not necessarily imply substandard care, but may be a warning sign that ought to be elucidated. The lack of or defective documentation may be a limitation of this study and consequently the results of our study should be interpreted with caution. However, detailed notes of advanced life-support actions are mandatory according to the Patient's Bill of Rights. Despite the difficulties associated with the prioritisation of documentation in these stressful situations, it is necessary. This is particularly critical in severe cases in which questions often arise regarding the time frame for the injury (antenatal, perinatal or postnatal) and also whether substandard care or even malpractice in conjunction with labour has taken place. ${ }^{8}$ To facilitate reliable documentation and evaluation in the future, we suggest the implementation of a simple and straightforward preprinted protocol and/or the recording by a video camera mounted on top of the resuscitation table of all neonatal resuscitations. ${ }^{910}$

With improved neonatal care as the prime goal, systematic audits such as these can be beneficial. During the last 10 years, mandatory neonatal resuscitation skills training has been introduced. This training has focused on increased knowledge about as well as anticipation of complications during labour, early paging for specialist assistance, team communication, documentation and also specific procedures such as ventilation and heart compression. Due to the constant risk of unexpected asphyxia, it is necessary that all staff involved in the management of the newborn is continuously trained in how to anticipate and handle complications in conjunction with labour while awaiting the arrival of more skilled personnel. ${ }^{11}$

Nevertheless, it is important to try to evaluate the effectiveness of the team and its compliance with the guidelines relating to neonatal resuscitation from the data in hand. The crucial period for improvement in cases of severe asphyxia at birth is a maximum of $10 \mathrm{~min}$, and it is therefore necessary that midwives and obstetricians in the delivery unit initiate immediate ventilation and also that more skilled members of staff participate within a few minutes. ${ }^{6}$ Since ventilation is the most important intervention in cases of neonatal resuscitation, we consider the most perturbing findings to be the documented delay in the arrival of professionals skilled in neonatal ventilation. We were unable to determine why some infants were late in receiving endotracheal intubation but one reason may be the late paging of skilled staff together with the lack of possibility to prepare for this intervention. Other explanations for this finding include satisfactory mask ventilation or intubation failure. In our study, it was noted that resuscitation was delayed by the absence of skilled professionals in 21 of 121 vaginal deliveries with complications noted before delivery in which a depressed infant could have been foreseen. In addition, in 27/124 deliveries with unexpectedly asphyxiated infants, a skilled physician had not arrived to assist resuscitation within the stipulated $4 \mathrm{~min}$ after birth and this may have aggravated the asphyxia.

Even if the majority of protocol deviations defined in this study are uncontroversial, failure to interrupt resuscitation after 15 or $30 \mathrm{~min}$ is contestable. There could have been clinical situations in which the attending physician may have considered continued resuscitation despite a longstanding asystole or persistent apnoea. For example, the parents may have opposed the discontinuation of resuscitation. Drugs administered to the mother immediately before delivery may have depressed spontaneous breathing in the newborn infant, thus demanding continued artificial ventilation after birth. An unclear diagnosis of intrapartum asphyxia - for reasons other than depressant drugs - may also have contributed to a decision to continue resuscitation beyond the stipulated point of no return.

An acid-base status immediately after birth was available in $81 \%$ ( $n=255$ ) of infants. The value of the correction of metabolic acidosis in newborn infants has been questioned and in more recent versions of guidelines for neonatal resuscitation, buffer therapy is not routinely recommended. ${ }^{12}$ However, during the study period, buffer therapy was still recommended in depressed infants and 176 infants were treated with buffer but the time point for the correction of acidosis was noted in only $38 \%$. The point of time for the correction of acidosis was missing in too many cases to allow for the provision of meaningful information regarding whether the time point for acidosis correction could be related to outcome or not.

We have previously reported that low Apgar scores at $5 \mathrm{~min}$ utes of postnatal age could have been prevented in approximately $40 \%$ in this group of 313 infants if substandard care during labour had been avoided. ${ }^{5}$ This is an important observation since recent long-term follow-up studies have shown that irrespective of whether the resuscitated infants recover without HIE, these infants have an increased risk of a low IQ and/ or cognitive dysfunctions later in life. ${ }^{13-15}$ Prerequisites and guidelines for safe delivery vary between delivery units and parts of the world, but some recommendations could improve 
neonatal outcome in general. First, since many circumstances causing severe asphyxia are predictable and may be preventable, we propose that the professionals in charge (anaesthesiologist, paediatrician and obstetrician) contact each other for reconciliation at least at the beginning of every shift to enable the anticipation of any complications. Second, we propose the introduction of an early paging routine (before birth) of the most skilled available staff when obstetrical complications or imminent asphyxia can be foreseen. Third, we recommend mandatory team training and skills training in fetal surveillance, obstetrical emergencies and neonatal resuscitation with a special focus on initiating extensive resuscitation. ${ }^{16}$ Finally, we suggest that simple guidelines and algorithms for the standardised operation of procedures should be readily available in the delivery unit.

In this study, only four infants were treated with hypothermia. Although hypothermia is nowadays evidence-based therapy to prevent adverse outcome after neonatal asphyxia, ${ }^{17}$ and despite the fact that significantly more than four of the infants included in the study fulfilled the criteria for cooling, the infrequent use of neonatal hypothermia can be explained by the fact that this therapy had not been established as a customary standard of care during the 2004-2006 study period.

\section{CONCLUSIONS}

Substandard care in conjunction with childbirth is not confined to the cases of severe asphyxia that are filed for suspected malpractice. The neonatal resuscitation documentation was too poor in many cases to enable accurate and reliable evaluation and audit. Nevertheless, this study points to several possibilities for improvements in immediate neonatal resuscitation following delivery. The most important action to be taken is earlier paging for the assistance of skilled personnel in cases of complicated deliveries and in cases of unexpectedly depressed infants.

Contributors The study was planned by both authors. Sophie Berglund collected all data, carried out the main part of the analyses and drafted the manuscript. Mikael Norman assisted in the analyses, in the interpretation of the results and the revisions to the manuscript. The final version of the manuscript has been approved by both authors.

Acknowledgements The authors thank the Karolinska Institutet for generous postgraduate funding.

Funding The study was funded by the Karolinska Institutet postgraduate funding.

\section{Competing interests None.}

Ethics approval The study was approved by the Research Ethics Committee, Karolinska Institutet, Stockholm (no. 2008/1375).

Provenance and peer review Not commissioned; externally peer reviewed.

\section{REFERENCES}

1. Berglund S. Severe Asphyxia Due to Substandard Care During Labour. Thesis for Doctoral Degree. Stockholm: Karolinska Institutet, 2010.

2. Gluck PA, Rayburn WF. Patients Safety in Obstetrics and Gynecology: Improving Outcomes, Reducing Risks. Obstetrics and Gynecology Clinics of North America. Volume 35. Philadelphia, PA: Elsevier 2008.

3. Berglund S, Norman M, Grunewald C, et al. Neonatal resuscitation after severe asphyxia - a critical evaluation of 177 Swedish cases. Acta Paediatr 2008;97:714-19.

4. Lawn JE, Kerber K, Enweronu-Laryea C, et al. 3.6 million neonatal deaths - what is progressing and what is not? Semin Perinatol 2010;34:371-86.

5. Berglund S, Pettersson $\mathrm{H}$, Cnattingius $\mathrm{S}$, et al. How often is a low Apgar score the result of substandard care during labour? BJOG 2010:117:968-78.

6. American Heart Association. 2005 American Heart Association (AHA) guidelines for cardiopulmonary resuscitation (CPR) and emergency cardiovascular care (ECC) of pediatric and neonatal patients: pediatric basic life support. Pediatrics 2006;117:e989-1004.

7. Thornberg E, Thiringer K, Odeback A, et al. Birth asphyxia: incidence, clinical course and outcome in a Swedish population. Acta Paediatr 1995:84:927-32.

8. Berglund S, Grunewald C, Pettersson H, et al. Severe asphyxia due to deliveryrelated malpractice in Sweden 1990-2005. BJOG 2008:115:316-23.

9. O'Donnell CP, Kamlin CO, Davis PG, et al. Ethical and legal aspects of video recording neonatal resuscitation. Arch Dis Child Fetal Neonatal Ed 2008;93:F82-4.

10. Gelbart B, Barfield C, Watkins A. Ethical and legal considerations in video recording neonatal resuscitations. J Med Ethics 2009;35:120-4.

11. Finer NN, Rich W. Neonatal resuscitation: toward improved performance. Resuscitation 2002;53:47-51.

12. International Liaison Committee on Resuscitation. The International Liaison Committee on Resuscitation (ILCOR) consensus on science with treatment recommendations for pediatric and neonatal patients: neonatal resuscitation. Pediatrics 2006;117:e978-88.

13. Lindström K, Hallberg B, Blennow M, et al. Moderate neonatal encephalopathy: pre- and perinatal risk factors and long-term outcome. Acta Obstet Gynecol Scand 2008;87:503-9.

14. Lindström K, Lagerroos P, Gillberg C, et al. Teenage outcome after being born at term with moderate neonatal encephalopathy. Pediatr Neurol 2006;35:268-74.

15. Odd DE, Lewis G, Whitelaw A, et al. Resuscitation at birth and cognition at 8 years of age: a cohort study. Lancet 2009;373:1615-22.

16. Draycott $\mathrm{T}$, Sibanda $\mathrm{T}$, Owen $\mathrm{L}$, et al. Does training in obstetric emergencies improve neonatal outcome? BJOG 2006;113:177-82.

17. Azzopardi DV, Strohm B, Edwards AD, et al. Moderate hypothermia to treat perinatal asphyxial encephalopathy. N Eng/ J Med 2009;361:1349-58. 